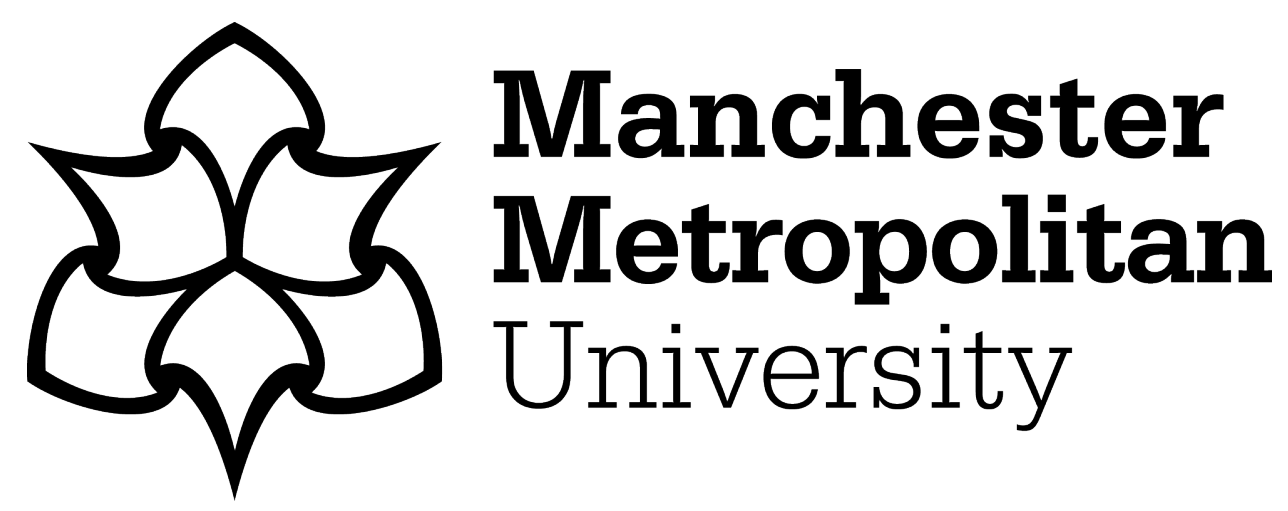

Aylen, J, Albertson, K and Cavan, G (2014) The impact of weather and climate on tourist demand: the case of Chester Zoo. Climatic Change, 127 (2). pp. 183-197. ISSN 0165-0009

Downloaded from: https://e-space.mmu.ac.uk/621368/

Version: Accepted Version

Publisher: Springer

DOI: https://doi.org/10.1007/s10584-014-1261-6

Please cite the published version 


\title{
The impact of weather and climate on tourist demand: The case of Chester Zoo
}

Jonathan Aylen ${ }^{1} \&$ Kevin Albertson 2 \& Gina Cavan ${ }^{3}$

\begin{abstract}
Warmer, drier summer weather brought by global climate change should encourage use of outdoor leisure facilities. Yet few studies assess the effect of current weather and climate conditions upon visits to leisure attractions.

Statistical time series models are used to analyse the short-run impact of weather and the long-run impact of climate upon visits to Chester Zoo, England. Temperature has a non-linear effect on visit levels. Daily visits rise with temperature up to a threshold around $21^{\circ} \mathrm{C}$. Thereafter visitor numbers drop on hot days. Visits are redistributed over time in accordance with the weather. Visitors discouraged by rainy weather one day turn up later when the weather improves. Otherwise, visitor behaviour is mainly influenced by the annual rhythm of the year and the pattern of public and school holidays. Out-of-sample tests suggest almost $70 \%$ of the variation in visit levels can be explained by the combination of weather and time of year.

Climate change is likely to redistribute visitors across the year. But it does not follow that "summer" visitor behaviour will transfer to spring and autumn. Day length, existing patterns of human activity and availability of leisure time constrain visit levels regardless of better weather. The main implication of potential climate change is the need for physical adaptation of the tourist environment as temperatures rise and rainfall diminishes in summer.
\end{abstract}

\section{Introduction}

Warmer, drier summer weather brought by global climate change might be expected to encourage use of outdoor leisure facilities. It has long been suggested that weather and climate play a key role in both the supply- and demand-side of the tourism system (e.g. Perry 1972; Mathieson and Wall 1982; de Freitas 2003). Climate is one of the environmental resources on which tourism depends influencing its location, supporting recreational activities, and often an attraction in its own right (Gómez Martín 2005). Tourists are affected by weather and climate in their decision-making process, including destination choice and selected activity (Giles and Perry 1998).

1 Manchester Institute of Innovation Research, Manchester Business School, Harold Hankins Building, The University of Manchester, Manchester M13 9PL, UK

jonathan.aylen@manchester.ac.uk

2 Department of Accounting, Economics and Finance, Manchester Metropolitan University, Manchester M15 $6 \mathrm{BH}, \mathrm{UK}$

3 School of Science and the Environment, Manchester Metropolitan University, John Dalton Building, Chester Street, Manchester M1 5GD, UK 
The relationship between key climate parameters and tourism has been researched for over 30 years (Scott et al. 2008a). Whilst tourists respond to the integrated effects of the atmospheric environment, including thermal, physical and aesthetic aspects (de Freitas 2003), many studies conclude that temperature is the dominant climate variable for tourism (e.g. Maddison 2001; Lise and Tol 2002; Bigano et al. 2006). Several studies have attempted to identify the ideal or optimum temperatures for tourism. Lise and Tol (2002) conclude that' globally, tourists prefer an average daily temperature of $21^{\circ} \mathrm{C}$, and ideal temperatures for urban sightseeing in Europe have been found at 20$26^{\circ} \mathrm{C}$ (Wilson et al. 2008; Rutty and Scott 2010). Higher daily maximum temperatures around $30^{\circ} \mathrm{C}$ are preferred for beach-based recreation (Maddison 2001).

In reality, such weather thresholds are value judgements made by individuals (Perry 2004), and depend on a number of factors including type of activity, clothing worn, age, and cultural background. Rainfall (or absence of rain) is also an important weather variable in determining participation in activities (Scott et al. 2008b). The timing of rain events is also considered influential. Scott and Jones (2007) find that morning rain affects participation levels more than afternoon rain for golf. Yu et al. (2009) emphasise that factors such as thunderstorms and showers may be as important as temperature when making travel choices. Weather parameters such as cloud cover also affect aesthetics and perceptions of a tourist destination (e.g. Morgan and Williams 1999).

Few attempts have been made to assess systematically the effect of weather upon daily visitor activity at the destination level. Yet we need to know the impact of weather on tourist activity before we can establish the potential impact of climate change on tourist numbers. Despite this, much recent research on climate and tourism relationships focuses on predicting tourist demand and flows for both domestic (e.g. Rosselló-Nadal et al. 2011) and international tourists (e.g. Lise and Tol 2002; Hamilton et al. 2005; Bigano et al. 2006) and the impact of global climate change on the demand for destinations (Scott et al. 2004; Amelung and Viner 2006).

Tourists respond differently to weather and climate. Whilst decision-making for tourism (destination and time period selection) is dependent on climate information, recreationists and day visitors are more weather-dependent, as their decision to travel is often made at short notice and plans can be adjusted according to short-term forecasts (McEvoy et al. 2006). Survey data from the hot summer of 1995 in the UK confirms the spontaneity of recreation decisions, since $52 \%$ of respondents took more day trips, $33 \%$ took more weekend/short breaks and less than $15 \%$ changed their main vacation plans (Agnew and Palutikof 2001). Brandenburg and Arnberger (2001) argue that further data is required to analyse the relationship between recreation and weather. Long runs of daily data are seldom available for outdoor leisure facilities.

So, from a UK perspective, whilst weather and climate may not be the primary motivation for taking a long domestic holiday, good weather is a significant factor in deciding to take a short break or day trip. Climate change projections for northwest England suggest hotter, drier summers and warmer, wetter winters (Murphy et al. 2009). By the end of the $21^{\text {st }}$ Century, annual mean temperatures are projected to rise by between 2.5 and $5.7^{\circ} \mathrm{C}$ (10 and $90 \%$ probability levels, under the IPCC A1FI scenario), with more frequent occurrences of extreme temperatures in summer (UK Climate Projections 2009). Projections for annual mean rainfall show little change, but an enhanced seasonal distribution, with summer rainfall projected to decrease by between $2 \%$ and $51 \%$, and winter rainfall projected to increase by between $9 \%$ and 50\% (10 and 90\% probability levels, under the IPCC A1FI 
scenario). In principle, warmer, drier summers and milder - if wetter - winters should benefit tourism and outdoor recreation. However, this is not guaranteed, and even in the short-run, it is not clear how potential visitors might respond to weather. While warm, dry days should encourage visits, hotter weather may drive potential visitors to cooler seaside destinations and participation in water-related activities (Smith 1993).

Weather-proofing tourist resources may also have an impact on visit levels. European tourist destinations market their attractions as robust to inclement weather. The zoo at Münster in Germany calls itself "Allwetterzoo". Analysis of weather and climate on visit rates for a particular attraction can help to establish its weather sensitivity and so improve management decisions at recreational sites (e.g. Changnon et al. 2002).

The impact of better weather is an empirical question. Here we examine the effect of daily weather on visits to a largely open-air zoo. Visits to outdoor sites are highly seasonal, so particular attention is paid to modelling of seasonality in the data.

\section{Explaining Visits to Chester Zoo}

Located in Northwest England $\left(53^{\circ} 13^{\prime} 36^{\prime} \mathrm{N}, 2^{\circ} 53^{\prime} 3^{\prime} \mathrm{W}\right)$, Chester Zoo opened in 1931 and is the UK's number one wildlife attraction, with around 8000 animals set within 45 ha of zoological gardens. The zoo receives around one million visits a year, an average of around 3,000 per day. Visits to Chester Zoo peak in August with fine weather and school holidays.

Our sample of visitors is drawn from Chester Zoo and covers 33 years of daily admissions data from $1^{\text {st }}$ January 1978 through to $31^{\text {st }}$ December 2010 . The zoo is typically closed to the public only on Christmas Day. Weather data includes daily rainfall and temperature data, obtained from local UK Met Office weather stations at Hawarden and Ness Gardens. We use the first 27 years of data to develop the model and leave the remaining six years as a holdout period to test the robustness of our model predictions.

The seasonal nature of visits to a countryside recreation facility is complex. Visit levels vary across the year due to seasonal variations in weather and the rhythm of holidays (Fig. 1). Weekly fluctuations reflect the pattern of the working week and the school week. Bank holidays further complicate the picture. These are statutory holidays in the UK, generally given on a Monday in the spring and summer. The date of Easter holidays varies between March and April. Our initial approach is to specify a model based on monthly data to describe the long-run effects of climate trends over the whole 27 year period. We go on to analyse daily data to establish precise weather effects and time of week effects.

The zoo was closed for 41 days during the foot-and-mouth epidemic of 2001. This natural experiment allows us to make inferences about the robustness of visitor intentions. After the period of closure, there was a recovery back to usual visit levels. The equivalent of 28 days' worth of visits was permanently lost, suggesting there was only a slight compensating "bounce-back" for visits missed during closure. The temporary but distinct impact of foot-and-mouth closure suggests it is a reasonable hypothesis that recreation visits to the zoo are not a random walk. (That is to say, a process in which the rational forecast for tomorrow's data is the same as the actual data observed today.) Perhaps the decision to visit a zoo is planned within the family ahead of time. This is 
consistent with evidence below and suggests the timing of zoo visits may be postponed if the weather is inclement on the chosen day, for up to two weeks, but not for much longer.

\section{Analysis of Seasonal Data}

\subsection{Time Series Properties and Stationarity}

A surprising feature of our data on visits to the zoo is its long-run stability (Fig. 2). Taking monthly data, both visit levels and weather appear stationary over the 27 year period used for estimation. That is to say neither the average or the variance in the level of visits, temperature and precipitation alters systematically over the long run. The statistical property of stationarity is important because if the mean or variance were changing systematically, forecasts of future visits would need to take this into account. The weather at Chester Zoo arguably appears to have got warmer over time - at least since 1987 - but this is not a statistically significant trend. These findings are consistent with Perry (2006) who also finds no trend in mean temperatures before 1987, and no significant changes in annual precipitation, and Thompson (1999) who finds no particular trend to precipitation in the British Isles over the last 150 years, although there have been substantial variations from year to year as well as significant seasonal changes (Perry 2006).

Assessing shifts in weather is controversial (Woodward and Gray 1995; Mills 2010). Long-run climate trends may be difficult to identify statistically because of the effect of variations in day-to-day weather. There is no apparent long-run change in weather patterns in our data. Similar findings are reported by Kallache et al. (2005) in the context of flood behaviour and Albertson et al. (2009) assessing UK wildfire incidence. However, Mills $(2010,424)$ cautions that well specified univariate time series models adapt very quickly to short-run movements in temperature and so do not predict longer run increases in temperature. In sum, a gentle long run trend is difficult to describe because of short-run fluctuations.

Stationarity of our 27 year data set is confirmed by visual inspection of the autocorrelation functions of visitor numbers, "seasonally adjusted" using auxiliary regression equations in the conventional way. The presence of seasonal heteroscedasticity in the data (see 3.2 below) invalidates a conventional unit root test for stationarity (e.g. an Augmented Dickey Fuller test, or Hylleberg, Engle, Granger and Yoo test).

This technical result offers a key insight into visitor behaviour. There is no evidence of a change in overall attitudes towards either zoos or climate over time. Stationarity implies short-run decisions on visits are consistent with long-run behaviour. Seasonality is problematic in dynamic regression models: it is difficult to allocate observed seasonal effects between short-run variations across seasons within each year and slowly changing seasonal responses as visitor habits alter over time (Harvey and Scott 1994). Yet, we find visitor habits barely change over time. The crucial result is that the potential impact of climate change is no more than the sum of short-run responses to weather.

\subsection{Seasonality in the Mean and Seasonal Heteroscedasticity}

Seasonality can take various forms in time series models (Franses 1996). The simplest form is deterministic seasonality where a dummy variable is used to capture the shift in mean from month to month. Stochastic seasonality is ruled out by the absence of a seasonal unit root in the monthly 
data. We also consider the possibility of a seasonal pattern in the variance of the data. If such a pattern exists, ordinary least squares inference is not valid.

We test for heteroscedasticity using a likelihood ratio test (Albertson and Aylen 1996). We reject the null-hypothesis of homoscedasticity, finding heteroscedasticity in the residual errors. This takes the form of severe seasonal heteroscedasticity by month, as well as some evidence of a change in variability of visit levels over time. There is a greater variability at the beginning and the end of the series and more consistent behaviour over the mid-period 1987 to 1995 (Table 1 and Fig. 2). During the late-1970s and early 1980s there was more extreme variation between peak and off-peak visit levels. More recently, special events at the zoo have increased off-peak visitor numbers, for instance a 10-km run in the quiet month of November. Precipitation also exhibits seasonal heteroscedasticity, reflecting changes in the mid-latitude westerly circulation (Mayes 1996). The heteroscedasticity problem is resolved by using White's heteroscedasticity-consistent covariance estimator - "White's method" (White 1980). We modify our hypothesis testing accordingly.

\section{Modelling the Pattern of Visits}

Our strategy is separately to explain monthly visit levels and daily visit levels using linear regression analysis. Modelling monthly visit levels allows us readily to capture seasonal changes in visit levels and to consider the long-run effects of climate trends over the whole 27 year period. Daily data enables us to establish precise weather effects and time of week effects.

Hypotheses are tested using a "general to specific" approach to model evaluation advocated by Hendry (e.g. Davidson et al. 1978; Gilbert 1986). This involves estimation of a very general model for visit levels, encompassing a wide range of weather and visitor related explanatory variables, and testing successive restrictions on these variables using specification tests. The resulting model should be consistent with knowledge about physical processes and human behaviour as well as accounting for the underlying statistical properties of the data set. Our initial general model for the monthly data is reported, given that our concern is hypothesis testing about weather. The final form of the forecasting model is reported in the case of daily data, showing how temperature and rainfall influence visitors from day-to-day.

\section{4:1 Monthly Data}

The level of visits to Chester Zoo is modelled using an autoregressive distributed lag model (ADL), with temperature, rainfall, lagged visits, holidays and special events as explanatory variables. This takes the general form:

$$
y_{t}=\alpha_{0}+\sum_{s=1}^{11} \alpha_{s} D_{s, t}+\sum_{j=0}^{p} \beta_{j} x_{t-j}+\sum_{i=1}^{q} \gamma_{i} y_{t-i}+\varepsilon_{t}
$$

where, in month $t: y_{t}$ is the monthly average number of visitors, $D_{s, t}$ takes the value unity if observation $t$ is in month $s$ and zero otherwise, $x_{t}$ is a vector of explanatory variables and $\varepsilon_{t}$ is a serially independent, normally distributed random element: the $\alpha s, \gamma s$ and $\beta s$ are parameters to be estimated.

The most striking feature of our model is the pattern of habitual behaviour revealed by the estimation. Results show for a general model (Table 2) that lagged visit levels over the past twelve 
months are a key explanatory variable, with significant coefficients on monthly lags up to one year ago. The persistence of visit levels can be explained by annual membership and by animal adoption schemes. The "Adopt an Animal" scheme lasts for a year, brings complimentary tickets and a timely reminder the adoption is due for renewal, which might well spark a repeat visit. Season tickets also allow members free admission for one year. There is a programme of regular talks and events. Typically, there are 25,000 members who visit eight times a year on average. Repeat visits account for at least one-fifth of the annual total of visits. A desire to make the most of the annual season ticket explains the strength of the eleventh and twelfth lag in the monthly model as members squeeze in a final visit before the expiry date. There are small but marginally significant autocorrelation lags in the function of visit levels at the twelfth, $24^{\text {th }}$ and $26^{\text {th }}$ months. The same echo shows up below in the analysis of daily data where there is evidence of repeat visits at six monthly and annual intervals. These econometric results confirm zoo membership is a powerful marketing tool. The loyalty of members accords with a similar finding for the UK that National Trust members are willing to travel significantly further to Trust-owned historic properties (where they enjoy free admission) than non-members (Aylen 1978).

Some months of the year perform better than might be expected given the weather and the presence of school holidays and bank holidays. Visit levels for May, July and August are higher than predicted. Monthly data is not powerful enough to distinguish the effect of days of the week. October and November see far more visits than might be expected, holding other factors constant, possibly because zoo members are keen to realise the full value of their subscription before expiry, which usually falls at the end of the calendar year.

The impact of weather is only transitory in the monthly model. Judging by monthly data, a $1^{\circ} \mathrm{C}$ rise in average mean monthly temperatures generates an extra five visitors per day and a $1 \mathrm{~mm}$ decrease in average monthly precipitation prompts an extra ten visitors per day. However, neither of these results are statistically robust. There is no evidence it is anything but the relative effects of weather, rather than absolute temperature and rainfall that influence tourists' decisions. What matters is if the weather is more (or less) clement than recent months. Changes in the weather merely shift visit timings around.

Crucially, both temperature and rainfall enter the equation with coefficients on the first lag variables that are virtually the arithmetic inverse of the coefficient on the contemporaneous variable. That is to say, last month's rainfall has the same absolute coefficient as this month's rainfall, but with the opposite sign. A Wald test on the twin restrictions that "the coefficients of temperature and precipitation; and lagged temperature and precipitation respectively, have the same absolute values but opposite signs" shows a statistic $\left(\chi_{2}^{2}\right.$ under the null) of 0.1520 (probability value of 0.93 ) suggesting we may accept the null. This implies change in temperature and change in rainfall across the months motivate visit levels. There is no long-run effect of climate over time. However, the short-run effect of rainfall and temperature is confirmed by analysis of the daily data, to which we now turn.

\section{4-2 Daily Data}

Daily observations allow us to focus on the immediate impact of the weather on visits. Again, we use an ADL model to capture dynamic effects as visitors respond to changes in temperature, rainfall and days of the week. We also test for threshold effects of hot, dry weather. The data is heteroscedastic, 
so we use robust covariance estimation to establish our final model (Table 3). General to specific modelling eliminates a large number of lags and moving averages included in the initial model.

Analysis of daily data shows both rainfall and temperature influence visits to the zoo in a non-linear way. Evidence suggests people prefer to visit when it is neither too cold nor too hot. When there is no rainfall, the optimum temperature is around $21^{\circ} \mathrm{C}$ on, say, a spring bank holiday (Fig. 3). The shape of the forecast function suggests people are slightly more responsive to temperatures above this optimum than below. This supports anecdotal evidence that potential visitors to the zoo head for waterside destinations on hot days.

Fixed effects are far more important than weather, although variables such as individual months may be picking up visitors' views about the weather at that time of year. In terms of partial R2, most of the variation in visit levels is explained by the autoregressive part of the model. For instance, the lag on visitor numbers for one or three days suggests the persistence of "spells" of clement or inclement weather. This is consistent with the fourth lag on daily visitor numbers being negative as changes in weather set in. Potential visitors postpone visits by up to four days in the face of rain. Rainfall in the British Isles is episodic and rain continues, often for three days - but no more than this (Chandler and Wheater 1998). So there is a rebound four days later. Rainfall reallocates visits over time as zoo visitors wait for drier weather. But the evidence of visitor response to prolonged closure during a foot and mouth epidemic implies visits are not deferred indefinitely.

There are strong day of the week effects, partly due to the pattern of school parties during the week. School trips are not distinguished separately in the data, but account for around one tenth of all visitors, mostly during mid-week school days between March and June. Both Mondays and Fridays are quiet and Saturdays see fewer visits than Sundays, which is consistent with anecdotal evidence from other zoos.

\section{Validating the Model with Out of Sample Predictions}

To assess the validity of our model, we use actual daily weather data for the six years 2005 to 2010 to predict visit levels at Chester Zoo. Hawarden Bridge weather station closed at the end of 2004, and data for a nearby weather station Hawarden Airport is incomplete. So we use weather observations from Ness Gardens on the Wirral to impute missing data for Hawarden Bridge. The two stations are nine miles apart, with the Gardens $33 \mathrm{~m}$ higher. Due to local effects, precipitation at the two stations show different seasonal patterns during an eleven year overlap period 1994 to 2004, but maximum temperatures do not differ significantly. We estimate a well specified deterministic seasonal transfer model to infer what rainfall and temperature would have been at Hawarden Bridge.

Using this set of explanatory data on temperature and precipitation we create out of sample forecasts for daily visit levels at Chester Zoo for the period 2005-2010 (Fig. 4) which are compared to the actual numbers reported by the Zoo. Weather and other seasonal variables explain almost $70 \%$ of the daily variation in observed visits over the six years. There is less volatility in the forecast visit numbers due to omission of special events. 


\section{Explaining Observed Patterns of Visitor Behaviour}

There is clear statistical evidence that warmer temperatures encourage visits, but only up to a threshold level around $21^{\circ} \mathrm{C}$, which strikingly echoes an insight of Lise and Tol (2002). In practice, temperature and rainfall have a relatively minor effect on visits to this outdoor attraction (Richardson and Loomis, 2004). These findings are subject to a caveat from Scott et al. (2008b) that perceived optimum climatic conditions vary across temperate tourism environments. De Freitas et al. (2008) suggest visitation levels or occupancy rates may not be suitable for establishing relationships between climate and tourism, since they are not necessarily a measure of satisfaction. So it may be wrong to generalise this result. The main finding is the importance of seasonal visit patterns. Zoo visits are characterised by habitual behaviour and a high level of repeat visitors. Visits seem to be postponed if the weather is inclement on the initial, chosen visit date.

These observed visitor patterns at Chester Zoo are consistent with time-budget studies over the last 30 years which show people are becoming more specialised in their use of time (Warde et al., 2004). Compared with earlier years, people now focus more time and money on their chosen leisure activity, but with fewer participants in each activity. In the case of excursions to the countryside, fewer choose to spend time in this way, but adherents are willing to devote more time to visits.

There may now be fewer zoo enthusiasts, but those who are keen on animals are willing to spend more time seeking them out and travel further to see them more frequently. Visitors to zoos fall into the cultural class of "family day trippers" (Sturgis and Jackson 2003) on the basis of the UK 2000 Time Use Survey. Family day trippers tend to be younger adults and have higher educational qualifications than others in the Survey. This suggests zoo visitors are now better informed, more sophisticated about conservation issues and more committed to learning than casual visitors in the past. Enthusiasm may diminish their sensitivity to the weather.

\section{Conclusions and Implications}

This paper reports development of statistical time series models to analyse both the short-run impact of weather and the long-run impact of climate upon visitors to Chester Zoo in northwest England. Warmer, drier summers brought by global climate change have been suggested as an opportunity to promote zoo visits.

The paper uses a comprehensive data set on daily visits to Chester Zoo covering a 33 year period. A statistical time series model is used to analyse both the short-run impact of weather (specifically, temperature and precipitation) and the longer-run impacts of climate trends upon visitor activity. Dynamic autoregressive distributed lag (ADL) models are developed to show how visit levels and weather interact both from month-to-month and day-by-day. An ADL model uses lagged values of the dependent variable as explanatory variables. Past visit levels are a key explanatory factor. Other causal variables such as weather also appear with such lags as testing suggests appropriate. It is possible to establish how far trips to the zoo are postponed rather than cancelled altogether due to inclement weather.

Visitor behaviour is mainly influenced by the annual rhythm of the year and the pattern of school holidays and bank holidays. There is evidence that visits are redistributed over short periods of time in accordance with the weather: Visitors, frustrated by rainy weather one day, turn up later when 
the weather improves. Warmer temperatures encourage visits, but only up to a threshold level around $21^{\circ} \mathrm{C}$. There is no evidence of a long-run shift in behaviour due to climate trends, just an immediate response to each day's weather. Visitors wait for drier days and avoid scorching sunshine - or at least, "scorching" by English standards.

Visits are dominated by habit in a way that is consistent with long-run changes in use of leisure time in the UK. The evidence is consistent with fewer but more enthusiastic visitors who come more often and, perhaps, stay longer. At Chester Zoo, development of annual membership and animal adoption encourage a high level of repeat visits. The loyalty of these visitors accords with the finding that leisure participants in the UK are becoming more specialised in their choice of activity.

We hesitate to generalise these results. The pattern of zoo visits may be atypical because of loyalty of visitors. Comparisons with a coastal attraction would test anecdotal evidence of visitors shifting to the coast as temperatures increase. The impact of climate change on tourism is likely to be complex as warmer, drier weather first encourages and then deters visits, at least until people get acclimatised to hotter, more clement weather.

\section{Data Appendix}

Data on visits is courtesy of Chester Zoo. Weather data is from Hawarden Bridge, $10 \mathrm{~km}$ from Chester Zoo (NGR SJ 3314E 3694 N), from the Met Office Land Surface Observation Station, provided through the British Atmospheric Data Centre. This weather station closed at the end of 2004. Subsequent data is inferred from Ness Gardens (NGR SJ 3303E 3755 N) with missing observations interpolated on the basis of evidence from Hawarden Airport (NGR SJ $3341 \mathrm{E} 3646$ N). Precipitation is in $\mathrm{mm}$ and temperatures in degrees Celsius, unless stated. School holiday dates are for the City of Salford, one of many school districts in the visitor catchment area.

Acknowledgments: The paper was part of a project on "Climate Change and the Visitor Economy in England's Northwest" funded by DEFRA, the Environment Agency and the former NWDA. The advice of management at Chester Zoo and the considerable help of six anonymous but diligent referees from earlier submissions to this journal are warmly acknowledged. 


\section{References}

Agnew MD, Palutikof JP (2001) Climate impacts on the demand for tourism. In: Matzarakis, A and de Freitas, CR (eds.), Proceedings of the First International Workshop on Climate, Tourism and Recreation, International Society of Biometeorology, Porto Carras, Halkidiki, Greece, pp.41-50 <http: //www.mif.unifreiburg. de/isb/ws/report.htm> accessed 23 ${ }^{\text {rd }}$ May 2005

Albertson K, Aylen J (1996) Modelling the Great Lakes Freeze: forecasting and seasonality in the market for ferrous scrap. Int J Forecast 12(3): 345-359. doi: 10.1016/0169-2070(96)00669-3

Albertson K, Aylen J, Cavan G, McMorrow J (2009) Forecasting the outbreak of moorland wild fires in the English Peak District. J Environ Manag 90(8): 2642-2651. doi: 10.1016/j.jenvman.2009.02.011

Amelung B, Viner D (2006) Mediterranean Tourism: Exploring the future with the Tourism Climatic Index. J Sustain Tour 14(4): 349-366. doi: 10.2167/jost549.0

Aylen J (1978) The social cost-benefit analysis of historic building restoration: a case study of Barlaston Hall, Staffordshire. In: Artis M, Nobay R (eds) Contemporary Economic Analysis. Croom-Helm, London, pp 409-447

Bigano A,Maddison D, Hamilton JM, Tol RSJ (2006) The impact of climate on holiday destination choice. Clim Chang 76(3-4): 389-406. doi: 10.1007/s10584-005-9015-0

Brandenburg C, Arnberger A (2001) The influence of the weather upon recreation activities, In: Matzarakis A, de Freitas CR (eds.) Proceedings of the First International Workshop on Climate, Tourism and Recreation, International Society of Biometeorology, Porto Carras, Halkidiki, Greece, pp.123-132 <http: //www.mif.unifreiburg. de/isb/ws/report.htm> accessed $23^{\text {rd }}$ May 2005

Chandler R E,Wheater H S (1998) Climate Change Detection using Generalized Linear Models for Rainfall - a case study from the West of Ireland, II. Modelling of Rainfall Amounts on Wet Days, University College London, Department of Statistical Science, Research Report no. 195, June, at <http: //www.ucl.ac.uk/Stats/ research/Resrprts/abs98.html> downloaded 20 th June 2005

Changnon D, Sparks J, Burgoyne A, Hahn C, Seymour R (2002) Enhancing swimming pool management decisions with climate information. Meteorol Appl 9(4): 461-468. doi: $10.1017 /$ S1350482702004097

Davidson J E H, Hendry D F, Srba F, Yeo S. (1978) Econometric modelling of the aggregate time-series relationship between consumers' expenditure and income in the United Kingdom, Economic Journal, 88, 352, 661-692, url: http: //www.jstor.org/stable/2231972

de Freitas CR (2003) Tourism climatology: evaluating environmental information for decision making and business planning in the recreation and tourism sector. Int J Biometeorol 48(1): 45-54. doi: $10.1007 / \mathrm{s} 00484-003-0177-z$

de Freitas CR, Scott D, McBoyle G (2008) A second generation climate index for tourism (CIT): specification and verification. Int J Biometeorol 52(5): 399-407. doi: 10.1007/s00484-007-0134-3 
Franses PH (1996) Periodicity and Stochastic Trends in Economic Time Series, Oxford University Press

Gilbert CL (1986) Professor Hendry's econometric methodology. Oxf Bull Econ Stat 48(3): 283-307. doi: 10.1111/j.1468-0084.1986.mp48003007.x

Giles AR, Perry AH (1998) The use of a temporal analogue to investigate the possible impact of projected global warming on the UK tourist industry. Tour Manag 19(1): 75-80. doi: 10.1016/S0261-5177(97)00093-9

Gómez Martín MB (2005) Weather, climate and tourism a geographical perspective. Ann Tour Res 32(3): 571-591. doi: 10.1016/j.annals.2004.08.004

Hamilton JM, Maddison DJ, Tol RSJ (2005) Climate change and international tourism: a simulation study. Glob Environ Chang 15(3): 253-66. doi: 10.1016/j.gloenvcha.2004.12.009

Harvey A, Scott A (1994) Seasonality in dynamic regression models, Economic Journal, 104, 427, 1324-1345, url: http: //www.jstor.org/stable/2235451

Kallache M, Rust HW, Kropp J (2005) Trend assessment: applications for hydrology and climate research, Nonlinear Processes in Geophysics, 12, 2, 201-210, oai: hal.archives-ouvertes.fr: hal00302542

Lise W, Tol RSJ (2002) Impact of climate on tourist demand. Clim Chang 55(4): 429-449. doi: 10.1023/A: 1020728021446

Maddison DJ (2001) In search of warmer climates? The impact of climate change on flows of British tourists. Clim Chang 49(1-2): 193-208. doi: 10.1023/A: 1010742511380

Mathieson A, Wall G (1982) Tourism: economic, physical and social impacts. Longman, Harlow

Mayes J (1996) Spatial and temporal fluctuations of monthly rainfall in the British Isles and variations in the mid latitude westerly circulation. Int J Climatol 16(5): 585-596. doi: 10.1002/(SICI)10970088(199605) 16: 5<585: : AID-JOC24>3.0.CO;2-\#

McEvoy D, Handley J F, Cavan G, Aylen J, Lindley S, McMorrow J, Glynn S (2006) Climate Change and the Visitor Economy: the challenges and opportunities for England's Northwest, Manchester: Sustainability Northwest and Oxford: UKCIP

Mills TC (2010) 'Skinning a cat': alternative models of representing temperature trends: An editorial comment. Clim Chang 101(3-4): 415-426. doi: 10.1007/s10584-010-9801-1

Morgan R, Williams AT (1999) Video panorama assessment of beach landscape aesthetics on the coast of Wales. J Coast Conserv 5: 1,13-22. doi: 10.1007/BF02802735

Murphy JM, Sexton DMH, Jenkins GJ, Boorman PM, Booth BBB, Brown CC, Clark RT, Collins M, Harris GR, Kendon EJ, Betts RA, Brown SJ, Howard TP, Humphrey KA, McCarthy MP, McDonald RE, Stephens A, Wallace C, Warren R, Wilby R, Wood RA (2009) UK Climate Projections Science Report: Climate change projections. Met Office Hadley Centre, Exeter 
Perry AH (1972) Weather, climate and tourism. Weather 27(5): 199-203. doi: 10.1002/j.14778696.1972.tb04291.x

Perry AH (2004) Sports tourism and climate variability. Proceedings of the Second International Workshop on Climate, Tourism and Recreation, Crete, Greece, 8-11 June 2004.

Perry, M (2006) Climate Memorandum No 21. A spatial analysis of trends in the UK climate since 1914 using gridded datasets. Met Office, Exeter UK http: //www.metoffice.gov.uk/climate/uk/about/UK_climate_trends.pdf (accessed 5/9/2012)

Richardson RB, Loomis JB (2004) Adaptive recreation planning and climate change: a contingent visitation approach. Ecol Econ 50(1-2): 83-99. doi: 10.1016/j.ecolecon.2004.02.010

Rosselló-Nadal J, Riera-Font A, Cárdenas V (2011) The impact of weather variability on British outbound flows. Clim Chang 105(1-2): 281-292. doi: 10.1007/s10584-010-9873-y

Rutty M, Scott D (2010) Will the Mediterranean Become "Too Hot" for Tourism? A Reassessment. Tour Hosp Plan Dev 7(3): 267-281. doi: 10.1080/1479053X.2010.502386

Scott D, McBoyle G, Schwartzentruber M (2004) Climate change and the distribution of climatic resources for tourism in North America. Clim Res 27: 2,105-117. doi: 10.3354/cr027105 Scott D, Amelung B, Becken S, Ceron J, Dubois G, Gossling S, Peeters P, Simpson M (2008a) Climate change and tourism: Responding to global challenges. World Tourism Organisation: Madrid, Spain and United Nations Environment Programme: Paris, France.

Scott D, Gössling S, de Freitas CR (2008b) Preferred climates for tourism: case studies from Canada, New Zealand and Sweden. Clim Res 38(1): 61-73. doi: 10.3354/cr00774

Scott D, Jones B (2007) A regional comparison of the implications of climate change on the golf industry in Canada. Can Geogr 51(2): 219-232. doi: 10.1111/j.1541-0064.2007.00175.x

Smith K (1993) The influence of weather and climate on recreation and tourism. Weather 48(12): 398-404. doi: 10.1002/j.1477-8696.1993.tb05839.x

Sturgis P, Jackson J (2003) Examining participation in sporting and cultural activities: Analysis of the UK 2000 Time Use Survey, Phase 2, commissioned by the Dept. for Culture, Media and Sport, London, November <http:

//www.statistics.gov.uk/downloads/theme_social/DCMS_Phase_report.pdf $>$ accessed $1^{\text {st }}$ June 2005

Thompson R (1999) A time-series analysis of the changing seasonality of precipitation in the British Isles and neighbouring areas. J Hydrol 224(3-4): 169-183. doi: 10.1016/S0022-1694(99)00129-8

UK Climate Projections (2009) North West England key findings. Available at: http: //ukclimateprojections.defra.gov.uk/22203 (accessed 27/08/12).

Warde A, Southerton D, Olsen W, Cheng S (2004) The changing organization of everyday life in UK: evidence from time use surveys 1975-2000. <http: //www.statistics.gov.uk/events/tus/agenda.asp> (download paper) accessed $8^{\text {th }}$ June 2005 
White $H$ (1980) A heteroskedasticity-consistent covariance matrix estimator and a direct test for heteroskedasticity, Econometrica, 48, 4, 817-838 url: http: //www.jstor.org/stable/1912934

Wilson E, Nicol F, Nanayakkara L, Ueberjahn-Tritta A (2008) Public urban open space and human thermal comfort: The implications of alternative climate change and socio-economic scenarios. J Environ Policy Plan 10(1): 31-45. doi: 10.1080/15239080701652615

Woodward W, Gray H (1995) Selecting a model for detecting the presence of a trend. J Clim 8: 19291937. doi: 10.1175/1520-0442(1995)008<1929: SAMFDT>2.0.CO;2, 8

Yu G, Schwartz Z, Walsh JE (2009) A weather-resolving index for assessing the impact of climate change on tourism related climate resources. Clim Chang 95(3-4): 551-573. doi: 10.1007/s10584009-9565-7 
Fig. 1 Monthly visits to Chester Zoo.

(Monthly average of daily visits 1978-2006)

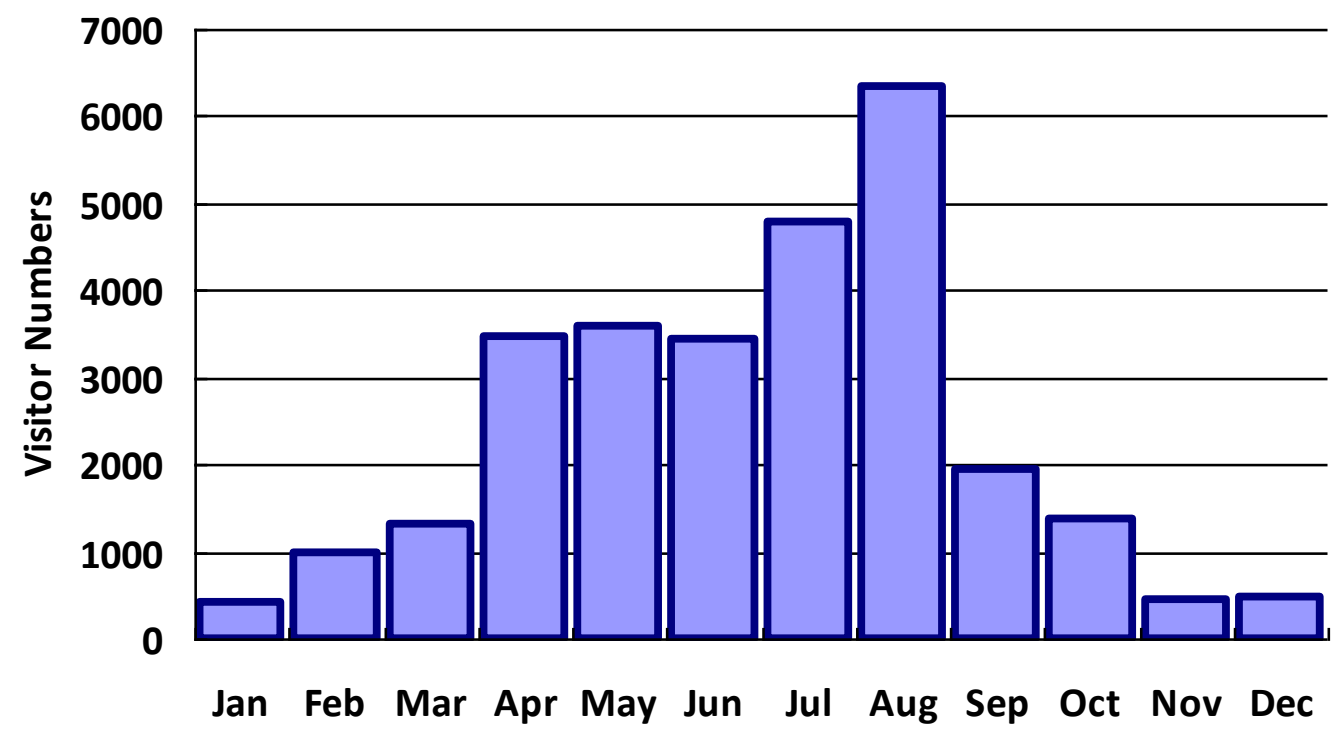


Fig. 2 Trends in visit levels to Chester Zoo.

(Monthly average of daily visits)

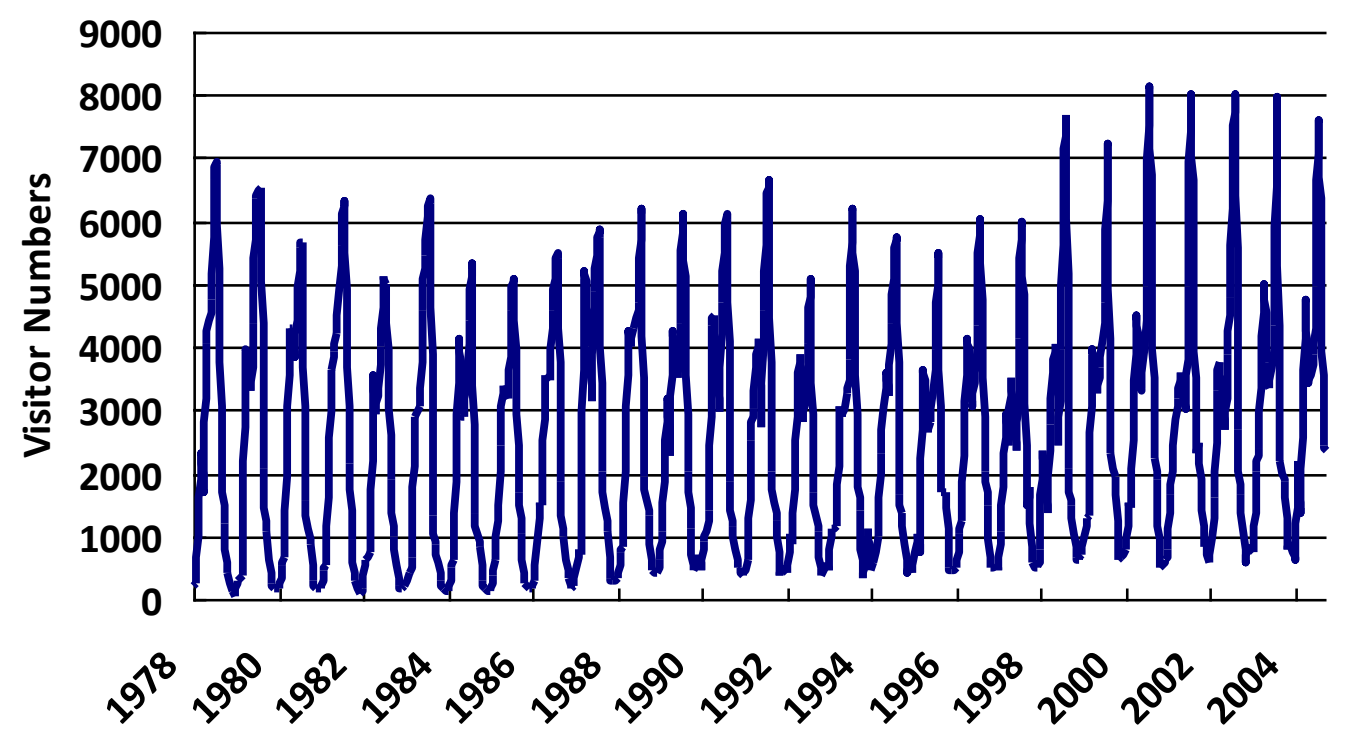


Fig. 3 visitor numbers and temperature.

Predicted visitor numbers: a "dry" (i.e. no precipitation) Spring Bank Holiday (end of May)

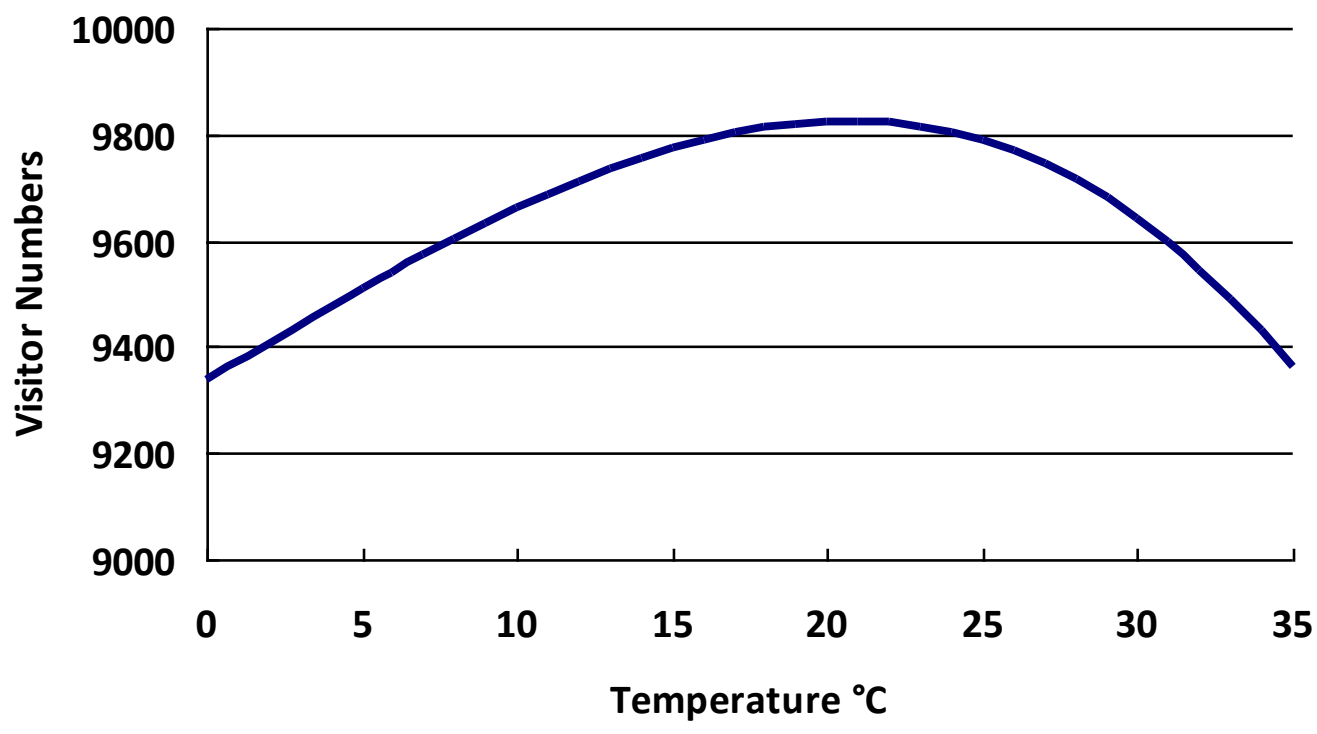


Fig. 4 Predicted versus actual visits to Chester Zoo, 2005 to 2010

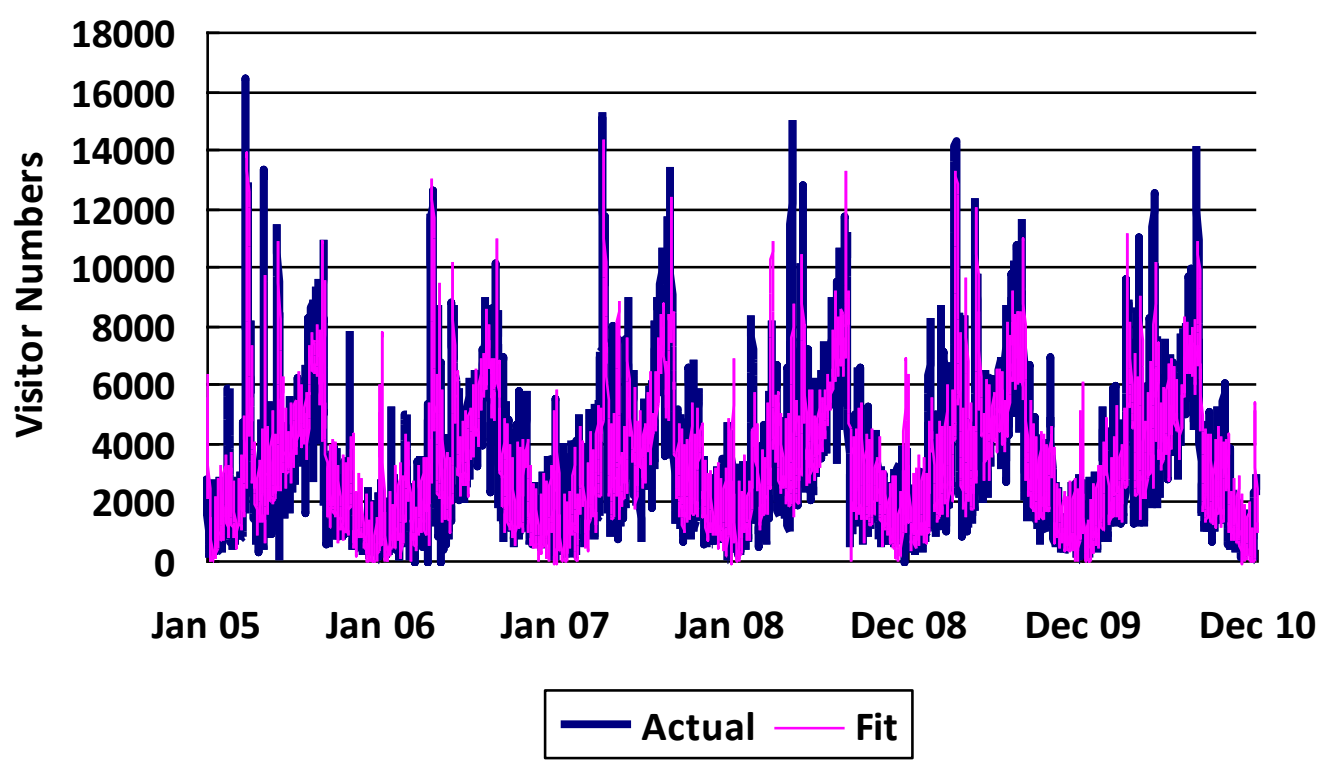


Table 1 Preliminary Tests on Heteroscedasticity of Monthly Visit Data

Likelihood Ratio test (monthly data)

seasonal heteroscedasticity

$\operatorname{Pr}\left(\chi^{2}{ }_{11}>19 \cdot 68\right)=5 \%$

$\operatorname{Pr}\left(\chi^{2}{ }_{11}>24 \cdot 73\right)=1 \%$

890

Visit numbers

Maximum temperature

Daily precipitation

(all monthly averages) sub-sample heteroscedasticity

$\operatorname{Pr}\left(\chi_{2}^{2}>5.99\right)=5 \%$

$\operatorname{Pr}\left(\chi_{2}^{2}>9 \cdot 21\right)=1 \%$

$6 \cdot 56$

$4 \cdot 25$

$4 \cdot 24$ 
Table 2 Monthly Visits to Chester Zoo. Initial ADL model of monthly visits to Chester Zoo, estimated in levels.

Sample period 1979 month 1 to 2004 month 10. 310 observations. Estimated using monthly data. Ordinary least squares estimation using White's heteroscedasticity adjusted standard errors

\begin{tabular}{|c|c|c|c|c|}
\hline Explanatory Variable & Estimate & Standard error & t-Ratio & [Prob] \\
\hline Visitors (L1) & $0 \cdot 221$ & 0.053 & $4 \cdot 19$ & {$[\cdot 000]$} \\
\hline Visitors (L2) & 0.082 & 0.048 & $1 \cdot 7$ & {$[\cdot 090]$} \\
\hline Visitors (L3) & -0.073 & 0.04 & $-1 \cdot 84$ & {$[\cdot 067]$} \\
\hline Visitors (L4) & -0.06 & 0.041 & $-1 \cdot 46$ & {$[\cdot 145]$} \\
\hline Visitors (L5) & 0.049 & 0.043 & $1 \cdot 15$ & {$[\cdot 250]$} \\
\hline Visitors (L6) & 0.082 & 0.036 & $2 \cdot 25$ & {$[\cdot 026]$} \\
\hline Visitors (L7) & $-0 \cdot 01$ & 0.037 & $-0 \cdot 277$ & {$[\cdot 782]$} \\
\hline Visitors (L8) & 0.007 & 0.04 & $0 \cdot 184$ & {$[\cdot 854]$} \\
\hline Visitors (L9) & -0.003 & 0.037 & -0.075 & {$[\cdot 940]$} \\
\hline Visitors (L10) & 0.095 & 0.041 & $2 \cdot 33$ & {$[\cdot 021]$} \\
\hline Visitors (L11) & $0 \cdot 106$ & 0.039 & $2 \cdot 72$ & {$[\cdot 007]$} \\
\hline Visitors (L12) & $0 \cdot 303$ & 0.063 & $4 \cdot 79$ & {$[\cdot 000]$} \\
\hline Tmax & $58 \cdot 8$ & $16 \cdot 1$ & 3.65 & {$[\cdot 000]$} \\
\hline $\operatorname{Tmax}(\mathrm{L} 1)$ & $-54 \cdot 2$ & $18 \cdot 3$ & $-2 \cdot 96$ & {$[\cdot 003]$} \\
\hline Precipita & -86 & $22 \cdot 5$ & $-3 \cdot 82$ & {$[\cdot 000]$} \\
\hline Precipita (L1) & 76 & $24 \cdot 2$ & $3 \cdot 14$ & {$[\cdot 002]$} \\
\hline Share of Saturday & -477 & 1640 & $-0 \cdot 291$ & {$[\cdot 772]$} \\
\hline Share of Sunday & 1290 & 1720 & 0.747 & {$[\cdot 456]$} \\
\hline Share of Bank Hols & 6930 & 2330 & $2 \cdot 98$ & {$[\cdot 003]$} \\
\hline Share School Hols & 1850 & 359 & $5 \cdot 16$ & {$[\cdot 000]$} \\
\hline Share Other Hols & 8710 & 3160 & $2 \cdot 75$ & {$[\cdot 006]$} \\
\hline Constant & -1540 & 513 & -3 & {$[\cdot 003]$} \\
\hline Trend & 0.858 & 0.326 & $2 \cdot 63$ & {$[\cdot 009]$} \\
\hline January & 179 & 329 & 0.546 & {$[\cdot 586]$} \\
\hline February & 285 & 403 & 0.708 & {$[\cdot 479]$} \\
\hline March & 616 & 396 & $1 \cdot 55$ & {$[\cdot 121]$} \\
\hline April & 779 & 429 & $1 \cdot 81$ & {$[\cdot 071]$} \\
\hline May & 1070 & 521 & $2 \cdot 05$ & {$[\cdot 041]$} \\
\hline June & 804 & 491 & 1.64 & {$[\cdot 103]$} \\
\hline July & 2110 & 527 & 4.01 & {$[\cdot 000]$} \\
\hline August & 2250 & 590 & $3 \cdot 82$ & {$[\cdot 000]$} \\
\hline September & 797 & 429 & $1 \cdot 86$ & {$[\cdot 064]$} \\
\hline October & 965 & 377 & $2 \cdot 56$ & {$[\cdot 011]$} \\
\hline November & 1500 & 306 & $4 \cdot 89$ & {$[\cdot 000]$} \\
\hline Event & 4170 & 3580 & $1 \cdot 16$ & {$[\cdot 246]$} \\
\hline Closed & -1490 & 197 & $-7 \cdot 55$ & {$[\cdot 000]$} \\
\hline Fuel Shortage & -2070 & 470 & $-4 \cdot 4$ & {$[\cdot 000]$} \\
\hline
\end{tabular}

$R^{2}=0.9614$, adjusted $R^{2}=0.9564$

LM test of residual serial correlation $16 \cdot 195\left(\chi^{2}{ }_{12}\right.$ under the null of serial independence)

Base month is December; $\mathrm{L}=$ monthly lag 


\section{Table 2 contd. Variable list (monthly data)}

Dependent Variable

Visitors dependent variable is average daily visit levels for that month

Explanatory Variables

Visitors (L1) \&c. visitors lagged by the number of months, e.g. Visitors (L12) is visits in the same month last year

Tmax average daily maximum temperatures for the month in ${ }^{\circ}$ Celsius

Tmax (L1) average daily maximum temperatures for the previous month

Precipita average daily precipitation in $\mathrm{mm}$

Precipita (L1) average daily precipitation for the previous month

No. of Sat, Sun ratio of Saturdays, Sundays to days in the month

Bank Hols ratio of Bank Holiday Mondays in the month

School Hols ratio of school holidays in the month, including weekends

other hols ratio of other holidays (e.g. royal weddings, Boxing Day)

Trend linear trend

January \&c. dummy variable for that month

Event ratio of one-off events in the month, such as $10 \mathrm{~km}$ run, Christmas lunches

Closed rare occasions when the zoo is closed, principally the foot-and-mouth outbreak of $26^{\text {th }}$ February 2001 to $6^{\text {th }}$ April 2001. Includes Christmas Day and royal funerals, expressed as a ratio of days in the month

Fuel Shortage ratios of periods of fuel shortage, $10^{\text {th }}$ September 2000 to $17^{\text {th }}$ September 2000 
Table 3 Final ADL model of daily visits to Chester Zoo, estimated in levels.

Sample period: 1 Jan 1978 to 1 Nov 2004, 9410 observations; estimated using daily data. Ordinary least squares estimation using White's heteroscedasticity adjusted standard errors.

\begin{tabular}{|c|c|c|c|c|}
\hline Explanatory Variable & Estimate & Standard error & t-Ratio & [Prob] \\
\hline Tmaxf2 & 0.552 & $0 \cdot 1062$ & $5 \cdot 2$ & {$[0 \cdot 000]$} \\
\hline Tmaxf3 & -0.005 & 0.0011 & $-4 \cdot 75$ & {$[0 \cdot 000]$} \\
\hline Prec & $-122 \cdot 650$ & 11.0498 & $-11 \cdot 1$ & {$[0 \cdot 000]$} \\
\hline Prec2 & $8 \cdot 254$ & $1 \cdot 1294$ & $7 \cdot 31$ & {$[0 \cdot 000]$} \\
\hline Prec3 & $-0 \cdot 153$ & 0.0253 & $-6 \cdot 03$ & {$[0 \cdot 000]$} \\
\hline Vnum_L1 & 0.385 & 0.0216 & $17 \cdot 85$ & {$[0 \cdot 000]$} \\
\hline Vnum_L3 & 0.092 & 0.0132 & $7 \cdot 02$ & {$[0 \cdot 000]$} \\
\hline Vnum_L4 & -0.058 & 0.0101 & $-5 \cdot 78$ & {$[0 \cdot 000]$} \\
\hline Vnum_L7 & 0.064 & 0.0098 & $6 \cdot 46$ & {$[0 \cdot 000]$} \\
\hline Vnum28a_3 & 0.063 & 0.0115 & $5 \cdot 5$ & {$[0 \cdot 000]$} \\
\hline Vnum28a_4 & 0.078 & 0.0128 & $6 \cdot 08$ & {$[0 \cdot 000]$} \\
\hline Vnum28a_5 & $-0 \cdot 113$ & 0.0159 & $-7 \cdot 07$ & {$[0 \cdot 000]$} \\
\hline Vnum28a_7 & 0.072 & $0 \cdot 011$ & $6 \cdot 59$ & {$[0 \cdot 000]$} \\
\hline Vnum28a_9 & $0 \cdot 107$ & 0.0169 & $6 \cdot 34$ & {$[0 \cdot 000]$} \\
\hline Vnum28a_10 & $-0 \cdot 130$ & 0.0195 & $-6 \cdot 65$ & {$[0 \cdot 000]$} \\
\hline Vnum28a_12 & $0 \cdot 114$ & 0.0129 & $8 \cdot 87$ & {$[0 \cdot 000]$} \\
\hline Vnum28a_13 & $0 \cdot 169$ & 0.0193 & $8 \cdot 74$ & {$[0 \cdot 000]$} \\
\hline Vnum28a_14 & 0.094 & 0.0187 & $5 \cdot 04$ & {$[0 \cdot 000]$} \\
\hline Monday & $-535 \cdot 290$ & $55 \cdot 415$ & $-9 \cdot 66$ & {$[0 \cdot 000]$} \\
\hline Friday & $-189 \cdot 274$ & $35 \cdot 5752$ & $-5 \cdot 32$ & {$[0 \cdot 000]$} \\
\hline Saturday & $225 \cdot 057$ & $42 \cdot 1331$ & $5 \cdot 34$ & {$[0 \cdot 000]$} \\
\hline Sunday & $1368 \cdot 081$ & $51 \cdot 2293$ & $26 \cdot 71$ & {$[0 \cdot 000]$} \\
\hline May & $836 \cdot 875$ & $115 \cdot 7244$ & $7 \cdot 23$ & {$[0 \cdot 000]$} \\
\hline July & $447 \cdot 658$ & $71 \cdot 7702$ & $6 \cdot 24$ & {$[0 \cdot 000]$} \\
\hline August & $1266 \cdot 754$ & 98.7293 & $12 \cdot 83$ & {$[0 \cdot 000]$} \\
\hline Schohol & $568 \cdot 767$ & $49 \cdot 2012$ & $11 \cdot 56$ & {$[0 \cdot 000]$} \\
\hline Holiday & $4986 \cdot 142$ & $292 \cdot 2761$ & $17 \cdot 06$ & {$[0 \cdot 000]$} \\
\hline Closed & $-1006 \cdot 205$ & $113 \cdot 1579$ & $-8 \cdot 89$ & {$[0 \cdot 000]$} \\
\hline Constant & $-1132 \cdot 344$ & $161 \cdot 7187$ & $-7 \cdot 00$ & {$[0 \cdot 000]$} \\
\hline Tmaxf2 & 0.552 & $0 \cdot 1062$ & $5 \cdot 2$ & {$[0 \cdot 000]$} \\
\hline Tmaxf3 & -0.005 & 0.0011 & $-4 \cdot 75$ & {$[0 \cdot 000]$} \\
\hline
\end{tabular}


Table 3 cont. Variable List (daily data):

Dependent Variable:

Vnum number of visitors to Chester Zoo that day

Explanatory Variables:

Tmaxf daily maximum temperature, estimated in degrees farenheit (to circumvent the problem of negative temperatures)

Tmaxf2 The square of Tmaxf

Tmaxf3 The cube of Tmaxf

Prec daily precipitation in $\mathrm{mm}$

Prec 2 The square of Prec

Prec 3 The cube of Prec

Vnum LX visitor numbers lagged X days (e.g. Vnum L1 is one day lag)

Vnum28a_X twenty eight day rolling average visitor numbers lagged by $X \times$ twenty eight days

Monday \&c. dummy variable for that day

May \&c. dummy variable for that month

Schohol dummy for school holiday day

Holiday dummy for all holidays

Closed dummy for daily closure 